\title{
Cross Correlation Analysis of Reward \& Punishment on Students Learning Behavior
}

\author{
Lubna Jabeen $^{1}$, Dr.Nadeem Iqbal ${ }^{2}$, Dr.Najib Haider ${ }^{3}$, Sajid Iqbal ${ }^{4}$ \\ ${ }^{1}$ Scholar Social Sciences Department Indus International Institute DG-Khan \\ ${ }^{2}$ Faculty of Management Sciences Ghazi University DG-Khan \\ ${ }^{3}$ Faculty of Statistics Ghazi University DG-Khan \\ ${ }^{4}$ Faculty of Management \& Social Sciences Indus International Institute DG-Khan \\ E-mail address: talhasaif22@gmail.com, sajid.edu@outlook.com
}

Keywords: Reward, Punishment, Learning behavior, Paired Sample

\begin{abstract}
The current study aims to investigate the impact of reward and punishment on students' learning behavior. This paper is quantitative in nature. The study used questionnaire approach and acquired data from school teachers of D.G Khan, are selected as sample of the study. The study used convenient and simple random sampling technique for data acquisition. Moreover, paired sample $T$ test approach is used to test correlation of variables. Hence it is concluded that both reward and punishment has positive significant impact on students' learning behavior whereas punishment has greater impact and role towards learning behavior.
\end{abstract}

\section{INTRODUCTION}

Effective education process depends on learning behavior of students. For today's teachers, students' learning behavior is a serious concern. With recent trends there are many activities to attract and distract the school students, they neglect their study and as a result they show meager performance in exams.

So, a teacher must know how to motivate, deal and to purify the learning potential of students by using different techniques. Teachers' methodology also plays a very pro-vital role to boost up the learning behavior of students.

But in opposite concerns students become habitual in less learning, paying lack of attention and being mantle absent. Thus, to take student away from such activities students are processed through punishment track. And past studies concluded punishment as negative attitudinal activity that reduces student performance and their participative behavior in class rooms.

Thus, it reveals the positive significant correlation of rewards and negative significant correlation of punishments with students' learning behavior. Reward is a qualitative and attitudinal value given in return for a good act. Reward as attitudinal value motivates individual's performance through its fundamentals. Rewards as reinforcement play a very important role to motivate the students towards learning.

Therefore a positive behavior is reinforced by reward (Sknner.1953). Barbetta, Norona and Bicard (2005), suggest that instead of reprimanding students, teachers should use non-verbal cues. These cues can be in the form of facial expressions, deliberately overlooking the behavior and diverting the attention of child to a positive subject.

Moreover, punishment is negative in this concern. And various investigations suggested various modes of punishment i-e verbal punishment, withdrawal of reward, penalties, extra homework, call to parents, insulting behavior and striking off by institute that reduces students performance.

The aim of current study is to explore the impact of rewards and punishment on the learning behavior of students. And to check the decisions with modern learning and motivational techniques used in schools. 
The purpose of the study is to investigate the role and impact of rewards and punishments towards the learning behavior of students in primary and elementary schools. And To find out that to what extant rewards and punishment should be applied in teaching learning process. And the study is vital in its nature although it is widely investigated yet it is less investigated in Asian context specifically in Pakistani region D.G Khan. This study will provide sufficient information and guidance to those teachers who are just entering in their teaching career, it will help to find out which type of rewards can be more effective to reinforce and motivate the students.

So the Scheme of this study consists of five parts. First part contains introduction, second part deals with review of literature, third part explains methodology, fourth part clarifies study result and analysis and fifth part elaborates the study findings, recommendation and practical implication.

\section{LITERATURE REVIEW}

Past investigation from few decades thoroughly investigated the effects of rewards and punishment on all aspects of school. Considering the importance of rewards and punishment in education researchers have conducted many studies focusing on the impact of these two techniques on students' learning behavior.

According to incentive theory of motivation, "people are pulled toward behaviors that offer positive incentives and pushed away from behaviors associated with negative incentives" (Bernstein, 2011)

Many educators and researchers have very different views on the effects of rewards as according to Deci, Koestner, \& Ryan (2001) rewards do not increase a student intrinsic motivation to learn.

Miller, Andy, Ferguson, Eamonn and Simpson, Rachel (1998) found in their study through a survey within one inner-city primary school of 49 pupils, six teachers and 64 parents or guardians shows parents and their children are strongly agree over the effectiveness of possible schoolinitiated rewards, but they are considerably disagree over the use of punishment or sanctions.

Asfia rehman, Dr. kamal haider ( 2013) explained in their study that learning is not possible without motivation and teachers usually used rewards and punishment as motivating factors to improve their students' learning in classrooms.

Ching, Gregory. S (2012) conducted a study to explore the characteristics of systems of rewards and sanctions in four Philippines schools and concluded that schools used rewards and penalties to create positive discipline and emphasis on the use of penalties for bad behavior rather than enhancing engagement and motivation. Students tended to perceive rewards to be strongly linked to work and penalties to behavior.

Dr. Cosmas MAPHOSA (2011) looked into insight of 125 educators selected from 15 independent schools in Eastern Cape Province of South Africa and found that educators viewed the use of punishment effective for controlling the learning behavior of students.

According to Pamela Oliver (1980), rewards and punishments are positive and negative incentive and both are essentially efficient for motivating others towards collective action but negative incentives have the potential side effects of disharmony and discord.

(Xinrui Yuan, Ling Che, 2012) concluded their research in these words, punishments and rewards, no matter how small, play a large part in molding and directing student misbehavior in the classroom. Although punishment has some shortcomings, it might be still the only effective action to some extremely troublesome behavior. So it should be used appropriately in order to maintain a positive classroom phenomenon. Moreover, they suggested that teachers should take appropriate steps to control the students 'behavior effectively, instead of punishment a positive good student teacher relationship should be built to assure the teaching learning progress.

Ilegbusi, M. I. (2013) explained that punishment has negative impact on students learning. Punishment is just a temporary drive. Students motivated by fear of punishment usually stop work once the fear is removed. So, it's difficult to use punishment effectively to motivate learning of students. 
Therefore, the model and hypothesis of the study are as follows,

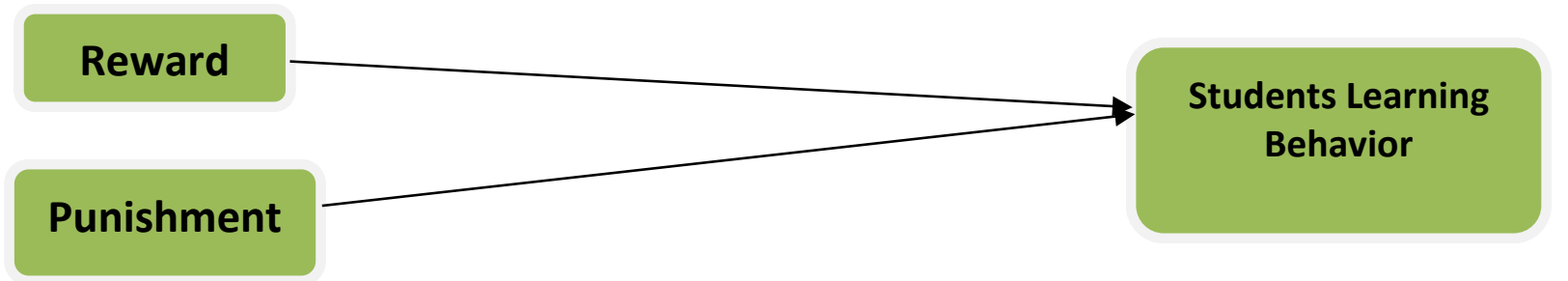

H1: There is positive significant impact of reward provision on students learning behavior

$\mathrm{H} 2$ : There is negative significant impact of punishment on students learning behavior.

\section{RESEARCH METHODOLOGY}

The current study is exploratory in nature and we want to explore the impact of reward and punishment on students' learning behavior. Where reward and punishment are independent variables and learning behavior is dependent variable.

In current study data is collected by questionnaire and the questionnaire used took as near as possible the same format as that of Miller, Andy, Ferguson, Eamonn and Simpson, Rachel (1998); \& Saleem (2012) slight alterations were made so that the rewards and punishments used would be known by respondents as being related to their school.

The data consists of 50 respondents that are punched for analysis and interpretation. Thus the population of the study consists of teachers, coworkers and supervisory staff of schools in southern Punjab, Pakistan. And the sample of current study consists on the teachers of primary and elementary schools of D.G. Khan. Moreover, the data is acquired through convenient and cluster random sampling of targeting male and female primary and elementary school teachers of D.G Khan context.

In current study we have used parametric techniques to qualify the result and findings by using paired sample $\mathrm{T}$ test on study data acquired through questionnaire that is based on 05 point likert scale. Thus such instrumentation is operated in statistical tool i.e SPSS.v.20.

\section{RESULTS \& ANALYSIS}

\section{(Descriptive Analysis)}

The frequency of male respondent i.e is 20 and female respondent i.e 30 from the sample area of D.G-Khan, while percentage of male respondents is 40 and of female is 60 respectively. Thus the valid and cumulative percentages are similar with actual percentages.

Table 1

Paired Sample Statistics

\begin{tabular}{cccc}
\hline Variable & MEAN & N & S.D \\
\hline P1 Reward & 1.83 & 50 & 0.38 \\
L.B & 1.85 & 50 & 0.44 \\
P2 Punishment & 2.65 & 50 & 0.296 \\
L.B & 1.85 & 50 & 0.44 \\
\hline
\end{tabular}

The table 1 represents the result of paired sample statistics where the mean of reward from pair 01 is 1.83 and L.B has 1.85. Moreover, the mean of punishment from pair 02 is 2.65 and L.B has 1.85 . Thus the sample frame is 50 and the value of S.D of reward from pair 01 is $0.38 \&$ L.B has 0.44 . The pair 02 reveals the S.D value of punishment as 0.296 and L.B value is 0.44 respectively. 
Table 02

Paired Sample T. Test

\begin{tabular}{ccccc}
\hline & \multicolumn{4}{c}{ Paired Differences } \\
\hline & Mean & S.D & Lower\% confidence Interval & Upper\% \\
Reward - L.B & -.017 & .58 & -.18 & .15 \\
Punishment- L.B & .801 & .54 & .65 & .96 \\
\hline
\end{tabular}

The table 02 represents the result of paired sample T. test where the mean of pair 01 (Reward L.B) is 0.017 and S.D is 0.58 . While the mean of pair 02 (Punishment - L.B) is 0.801 and S.D is 0.54. Likewise, the result has shown their higher percentage of pair 01 (Reward - L.B) as 0.15 with respect to lower percentage -0.18 that shows reward has significant positive contribution in L.B. Moreover pair 02 (Punishment - L.B) also has positive \& significant impact with the higher value as $0.96 \%$ with respect to lower value as 0.65 . Thus such significance of result is based on significance criterion as $95 \%$ significance level.

\section{STUDY CONCLUSION}

In current study we investigated the impact of rewards and punishments on learning behavior of primary and elementary school students. While the parametric techniques are used to test the response of acquired by D.G-Khan respondents that shown significant positive impact of rewards and punishments on learning behavior. While in D.G-Khan as an under developing area regarding educational reforms reward is comparatively less significant with L.B as compare to punishment. Moreover punishment has greater role towards learning behavior because of cultural traits, demographic needs and attitudinal differences as compare to Lahore, Karachi and Islamabad. Hence the study has shown significant correlation with past investigation.

\section{References}

[1] Deci.E, Koestner.R \& Ryan.R. (2001). Extrinsic rewards and intrinsic motivation in education. Review of Educational Research, vol.71, No.1

[2] Miller, et al, (1998). The perceived effectiveness of rewards and sanctions in primary schools. Journal of Education Psychology, Vol.18, No.1

[3] Rehaman.A, Haider.K. (2013). The impact of motivation on learning of secondary school students in Karachi. Educational Research International, vol.2, No.2

[4] Ching, \& Gregory.S. (2012). Looking into issue of rewards and punishment in students. International Journal of Research Studies in Psychology, vol.1, No.2

[5] MAPHOSA.C, (2011). Discipline versus punishment: Which way for educators in South African school? International Journal on New trends in Education and their implications, vol.2, Issue. 4

[6] Oliver.P, (1980).Rewards and punishments as selective incentives for collective action. American Journal of Sociology, vol.85, No.6

[7] Yuan.X, \& Che.L, (2012). How to deal with student's misbehavior in the classroom?Journal of Education and Developmental Psychology. Vol.2, No.1

[8] Illegbusi, \& M.I.(2013).An analysis of the role of rewards and punishments in motivating school learning. Computing, Information System \& Development Information, vol.4, No.1 